\title{
ÉTICA E FILOSOFIA PRÁTICA: PARA UMA ANÁLISE DAS POLÍTICAS SOBRE DIREITOS DOS IDOSOS EM SOCIABILIDADES CAPITALISTAS ENQUANTO MANIFESTAÇÃO DO CONFLITO ENTRE JUSTIÇA FORMAL E JUSTIÇA CONCRETA
}

\author{
ETHICS AND PRACTICAL PHILOSOPHY: FOR AN ANALYSIS \\ OF HEALTH POLICIES ON THE ELDERLY'S LAWS AT \\ CAPITALIST SOCIABILITIES AS A MANIFESTATION OF THE \\ CONFLICT BETWEEN FORMAL JUSTICE AND CONCRETE \\ JUSTICE
}

\author{
Michelli Barbosa do Nascimento* \\ Raquel da Silva Marinho Falcão** \\ Evandro Alves Barbosa Filho***
}

Recebido: 08/2017

Aprovado: 08/2017

\begin{abstract}
Resumo: O objetivo deste artigo é analisar a natureza do direito e da política social sob o capitalismo, a partir da crítica sobre um dos principais programas nacionais de saúde voltados a materializar o direito social à saúde dos idosos. Esforço fundamental para apreender as determinações e mediações acerca do tratamento da população idosa na sociedade capitalista. O estudo é qualitativo e resultado de pesquisa de campo e bibliográfica. Verificouse a imaterialidade do direito à saúde refletida numa visão liberal, isto é, formal dos direitos humanos a partir da crítica marxista a esse conceito, trabalhadas no método histórico dialético, apontando o embate entre a concepção dos direitos da pessoa idosa e a tensão no que diz respeito a sua efetivação, por uma política que minimiza a responsabilidade do Estado como parte de uma contrarreforma, tornando-se um espaço não de concretização dos direitos, mas de resposta à necessidade de reprodução capitalista.

Palavras-chave: Direitos sociais; idosos; política de saúde e política social.

Abstract: This article aims to analyze the bourgeois nature of rights and social policy under capitalism, based on a critique of one of the most important national health programs that aims to materialize the social right to health of the elderly. It's a fundamental effort to understand the determinations and mediations over the treatment of the elderly population in capitalist society. The study is qualitative and result of a field research and bibliographic review. It was verified the immateriality of the right to health according to the liberal approach, which means a formal vision of human rights. This is a conception criticized by Marxist's
\end{abstract}

\footnotetext{
* UFPE - Recife - PE, Brasil. Assistente Social. Membro do Grupo de Estudos sobre o Envelhecimento Humano na Perspectiva da Totalidade Social (GEEHPTS), da Universidade de Pernambuco, desde 2015. Membro da Comissão de Envelhecimento do Conselho Regional de Serviço Social. Mestra da Pósgraduação em Gerontologia/ PPGERO, Universidade Federal de Pernambuco/UFPE. Recife (PE), Brasil. Especialista em Intervenções Psicossociais com Grupos de Risco e Vulnerabilidade Social/FAFIRE. Coordenadora e docente do curso de graduação em Serviço Social do Centro Universitário Maurício de Nassau.michellibnascimentoas@gmail.com

** UFPE - Recife - PE, Brasil. Assistente Social. Doutora em Serviço Social pela Universidade Federal de Pernambuco/UFPE. Recife (PE), Brasil. Mestra em Comunicação pela Universidade Federal de Pernambuco/UFPE. Recife (PE), Brasil. Docente titular do Centro Universitário Maurício de Nassau. rf.3013@gmail.com

*** UFPE - Recife - PE, Brasil. Assistente Social. Mestre e Doutor em Serviço Social pela Universidade Federal de Pernambuco - UFPE. Pesquisador do Núcleo de Estudos e Pesquisas em Políticas Sociais e Direitos Sociais - NEPPS do Programa de Pós-Graduação em Serviço Social da UFPE. Pesquisador do Grupo de Pesquisa Práxis - Política, Planejamento e Gestão em Saúde da Universidade de Pernambuco UPE/CNPq.evealves85@yaahoo.com.br
}

Problemata: R. Intern. Fil. V. 8. n. 2 (2017), p. 138-157 ISSN 2236-8612

doi:http://dx.doi.org/10.7443/problemata.v8i2.35562 
approach, based on the dialectical historical method, which points out the clash between the conception of the rights of the elderly person and the tension in terms of its effectiveness, caused by a policy that minimizes the State's responsibility as part of a counter-reform. This trend makes the social policy become a space for the realization of rights, but a response to the need for capitalist reproduction.

Keywords: social rights; elderly people; health policy; social policy

\section{Introdução}

Uma das maiores conquistas culturais de um povo em seu processo civilizatório é o envelhecimento de sua população, refletindo uma melhoria das condições de vida. De acordo com projeções das Nações Unidas (Fundo de Populações) uma em cada 9 pessoas no mundo tem 60 anos ou mais, e estimase por volta de 2050 um crescimento para 1 em cada 5, proporcionando maior número de idosos que crianças menores de 15 anos. Entre 2005 e 2015, a proporção de idosos de 60 anos ou mais, na população do País, passou de 9,8\% para 14,3\%. Os dados são do estudo "Síntese de Indicadores Sociais (SIS): uma análise das condições de vida da população brasileira 2016" (BRASIL, 2016).

O aumento expressivo dessa população requer um atendimento voltado para este grupo social prevendo, inclusive, um possível crescimento das demandas aos sistemas de proteção e seguridade social, tendo em vista a sua maior vulnerabilidade física e social. De fato, uma das grandes criações do capitalismo tardio por meio das políticas estatais de sua fase monopolista é a de uma massa de trabalhadores idosos pauperizados, vítimas da lei geral de acumulação de capital, que expurga e precariza o trabalho. A criação desse "excedente" humano de idosos só pode ser viabilizada pela intervenção direta da forma política do capital: o Estado burguês (HIRSCH, 2010). Este, desde a crise estrutural do capitalismo de 1974 vem reduzindo suas funções de provedor dos direitos sociais de cidadania e ampliando as margens legais para exploração dos trabalhadores, inclusive de velhos(as) trabalhadores(as) ${ }^{1}$.

Foi no momento em que o chamado "milagre econômico brasileiro" (19671974) entrou em colapso junto com o projeto desenvolvimentista e os "30 anos gloriosos do capital" foram encerrados pela crise estrutural do capitalismo de 1974, que foi criado, naquele ano, o primeiro programa assistencial voltado à pessoa idosa da classe trabalhadora: O Programa de Assistência aos Idosos, com recursos de doações e da Legião Brasileira de Assistência - LBA². O público atendido eram pessoas com mais de 60 anos que fossem comprovadamente pobres (SPOSATI et al, 2014). Esta focalização na perspectiva de políticas sociais e direitos restritos que parece permanecer na atualidade, como na Política Nacional do Idoso, Lei o 8.842, de janeiro de 1994, e o Estatuto do 
Idoso, Lei ํo 10.741 de 2003, que reduzem a intervenção estatal às situações em que a família "falha" em garantir pela via do mercado o conjunto das necessidades protetivas e assistenciais a idosos (as). Esta expansão dos direitos e políticas sociais parece não tencionar as tendências do capitalismo em fomentar a justiça social restrita aos seus aspectos jurídico-formais.

Nesse sentido, os limites dos projetos político-partidários, mesmo dos partidos orientados às lutas da classe trabalhadora, se encontram na própria natureza burguesa do Estado, o que torna inexequível a proposta de um "socialismo jurídico" ou de uma "progressiva exposição das contradições da política sob o capitalismo e do Estado, e de pleito por questões necessárias às demandas objetivas da classe trabalhadora (ENGELS \& KAUTSKY, 2012).

Mesmo reconhecendo os limites dos direitos sob a sociabilidade do capital e o poder ideológico do discurso sobre estes como um mecanismo de passivização das classes e grupos subalternos, é preciso reconhecer o papel fundamental da implementação destes direitos na desmercantilização, mesmo que parcial, das necessidades das classes que vivem do trabalho. Necessidades estas que se aprofundam quando velhos e velhas trabalhadoras vivenciam 0 processo de envelhecimento a partir de lugares sociais de subalternidade. Neste sentido, o debate acerca da natureza ideológica e política das formas de intervenção do Estado brasileiro frente ao envelhecimento da sua população, inclusive entre os setores mais pauperizados é urgente.

Para a compreensão dessas condições, se faz necessária uma análise que envolva os processos de trabalho nas sociedades contemporâneas, as condições de vida dos que envelhecem e a conjuntura política e econômica num contexto globalizado. Segundo Beauvoir,

\footnotetext{
Nas democracias capitalistas, o envelhecimento da população suscita uma nova questão. (...) não somente as pessoas idosas são muito mais numerosas do que outrora, mas elas não se integram mais espontaneamente à sociedade; esta vê-se obrigada a decidir sobre o estatuto delas, e a decisão só pode ser tomada em nível governamental. A velhice tornou-se objeto de uma política. (BEAUVOIR, 1990, p. 273).
}

Mais do que compreender a rede de serviços fragmentados e escassos que se difundiram para esse grupo social, é necessário analisar o discurso do Estado brasileiro sobre o envelhecimento, desde que este começou a intervir sobre as refrações da questão pela via da provisão de serviços sociais, sobretudo, os de natureza assistencial (SPOSATI et al 2014).

Diante disso, não podemos deixar de citar que, desde 2011, o Ministério da Saúde, vem fomentando a expansão e consolidação da atenção domiciliar, como modalidade de assistência à saúde "humanizadora" e estratégica à redução da demanda por leitos hospitalares e cuidados de natureza 
ambulatorial. Analisando o novo Programa de Atenção à Saúde da Pessoa Idosa, considera-se que suas propostas pretendem: maximizar os resultados sem aumentar o financiamento da Política de Saúde; responsabilizar a família e a comunidade como atores do cuidado em saúde e considerar o domicílio um "ponto de cuidado" da rede de atenção à saúde (BARBOSA FILHO, LAFAYETTE \& NASCIMENTO, 2017).

Mesmo o direito à saúde, o único direito universal da seguridade social brasileira, vem sendo questionado em sua materialização por um discurso que repassa as responsabilidades do Estado com a provisão de cuidado e assistência à saúde à família e aos grupos primários. Como o próprio Programa de atenção domiciliar denominado "Melhor em Casa: a segurança do hospital no conforto do seu lar" defende o aumento da rotatividade dos leitos nas unidades de saúde e diminuir os gastos com tratamento e assistência médica. Este Programa Nacional propõe uma série de medidas que refuncionalizam os princípios e diretrizes do Sistema Único de Saúde - SUS, de acordo com a tendência observada por Soares (2010) de adoção de perspectivas e abordagens de saúde contrárias ao Projeto de Reforma Sanitária e à materialização do SUS como um direito de cidadania e dever do Estado (BARBOSA FILHO \& ROCHA, 2016; BRAVO, 2010).

Veja-se que, o "Melhor em Casa" é apenas um exemplo da contradição entre a existência do direito formal e a desigualdade objetivo-material na sociabilidade capitalista, reproduzida e legitimada por meio das políticas do Estado e dos aparelhos privados de hegemonia das classes dominantes. Nesse sentido, outras leis, oriundas do eixo da seguridade social da Constituição de 1988, que deveriam ter um papel central de garantia dos direitos deste público, vêm sendo tensionadas/questionadas pela dinâmica pauperizadora do capitalismo e do Estado neoliberal. Exemplo desse processo social é a descaracterização da racionalidade ideológica e política do Projeto Brasileiro de Reforma Sanitária, presentes nas Leis Orgânicas do SUS 8.080 e 8.142 ambas de 1990, em aspectos centrais dos seus princípios e diretrizes como o controle e a participação social da sociedade civil, a concepção ampliada de saúde e a integralidade de atenção à saúde. Estes elementos fundamentais vêm sendo substituídos por abordagens tecnicistas, pragmáticas, que legitimam a privatização do SUS e a transferência da saúde da condição de direito social a de serviço de natureza e responsabilidade privada, ocorrendo uma "americanização" da concepção de saúde, deslocada do Estado e da coletividade para o mercado e o indivíduo.

Vale salientar que, a implantação desse Programa de "contenção de demanda" ao Sistema Único de Saúde vem sendo realizada por governos de nível estadual e municipal, especialmente, por meio de parcerias público- 
privadas, criando novas determinações à intervenção dos trabalhadores da área da saúde, além de abranger uma grande quantidade de idosos (as) internados (as) ou não (BARBOSA FILHO; NASCIMENTO e SORIANO, 2013).

Como se vê, a prioridade é a "saúde fiscal" do Estado, cada vez mais austero em relação às necessidades sociais coletivas e mais ativo em relação às demandas de acumulação do capital, inclusive por meio da mercantilização dos direitos sociais, processo que David Harvey (2005) denominou de "acumulação por espoliação de direitos".

Diante do exposto, o objetivo deste artigo é analisar a natureza burguesa do direito e da política social, especificamente da política de saúde do idoso. Aqui, parte-se do pressuposto teórico-metodológico de que a negação ou a materialização do direito à saúde integral dos idosos por meio das políticas sociais é determinada por processos estruturais da sociabilidade capitalista em sua fase tardia: a redução e mercantilização das políticas sociais; a reestruturação produtiva; a contrarreforma do Estado e a hegemonia do pensamento neoliberal. $O$ trabalho é qualitativo e resultado do estudo bibliográfico oriundo de uma pesquisa acadêmica, realizada entre os anos de 2015 e 2016 em um dos primeiros programas de mestrado em gerontologia do pais. Este analisou a integralidade das ações em saúde de um serviço de atenção domiciliar junto a idosos assistidos neste serviço. Na busca pelas expressões das contradições e limites do direito dos idoso à saúde, a pesquisa de campo envolveu observação participante e entrevistas em profundidade realizadas com os trabalhadores de saúde, idosos usuários do SAD e cuidadores, geralmente membros dos grupos familiares desses idosos. É válido ressaltar que o estudo foi aprovado pelo Comitê de Ética em Pesquisa e que a mesma respeitou todos os aspectos éticos da pesquisa envolvendo seres humanos.

Um dos principais achados da pesquisa foi que a não efetivação integral do direito à saúde dos idosos é obstaculizado bem mais por limites estruturais das políticas e dos direitos sociais sob a sociabilidade capitalista do que por meras questões técnicas, administrativas ou gerenciais, como é defendido nos programas, políticas e pelos formuladores do "Melhor em Casa". Essa constatação levou os autores a analisar trabalhos clássicos e contemporâneos da teoria marxista para entender e socializar que limites estruturais são estes que reduzem os direitos sociais a abstrações e as políticas sociais em serviços sociais fragmentados e incipientes.

\section{A (des)estruturação da política de saúde à saúde: da reforma sanitária ao "sus possível"}


A política social é um espaço dialético de projetos contraditórios em confronto, constituindo-se em expressão da luta de classes no âmbito do Estado. Situada no espaço da reprodução social, a política social tem como cerne as relações de produção social, mantendo importantes conexões com as necessidades determinadas pelo modo de ser da sociedade (HARVEY, 2008; SOARES, 2010).

Nesse sentido, segundo Bravo (2006), na política de saúde há fundamentalmente dois grandes projetos em confronto: o projeto de reforma sanitária - hegemônico durante a formulação da Constituição de 1988, que garantiu o marco legal do SUS - e o projeto de saúde privatista - que ganhou preponderância na ditadura pós-64 e retomou sua hegemonia nos anos 1990. Este último possui uma racionalidade que também se faz presente na organização do SUS, vinculada aos interesses do mercado privado da saúde, com uma concepção de direito distinta da racionalidade do projeto de reforma sanitária.

A partir da pesquisa realizada por Soares (2010) existiriam não dois, mas três projetos distintos de política de saúde com implicações centrais à materialização dos direitos à saúde. Para a autora, além dos projetos supracitados a década de 2000 foi o cenário de surgimento do projeto denominado de "SUS Possível". Este "novo" projeto seria resultante das transformações ideológicas e políticas de antigas lideranças do movimento de reforma sanitária, que ao ocuparem espaços de poder dentro do Ministério da Saúde, passaram a legitimar à concepção do direito à saúde, como um direito à serviços básicos e de cobertura restrita.

A racionalidade hegemônica no SUS, nos anos 2000, expressa os princípios do "Projeto privatista" e "SUS possível" e tem fundamentos que reatualizam velhos conteúdos da racionalidade instrumental do Estado burguês. Dentro desse cenário iniciado com o neoliberalismo, os problemas e contradições do SUS são atribuídos às questões de âmbito administrativo/gerencial e de gestão, daí surgindo todo o discurso justificador das parcerias público-privadas para gerir a saúde, criando as possibilidades concretas do usufruto direto do fundo público pela iniciativa privada (BARBOSA FILHO, 2013; SOARES, 2010).

Conforme análise de Mota (2005), o projeto de reforma sanitária está vinculado aos interesses dos trabalhadores, enquanto que no projeto de saúde privatista o direito é um bem a ser consumido no mercado. No projeto de reforma sanitária o direito é concebido originalmente como público e universal, ao qual absolutamente todos devem ter acesso, constituindo-se dever do Estado a sua prestação. Assim, enquanto o primeiro está fundado na lógica da 
cidadania de direitos, no segundo a lógica é a da cidadania do consumo.

Em outras palavras, enquanto os sistemas nacionais de saúde liberais ou residuais argumentam que o mercado, a família e a rede de solidariedade próxima são os provedores ideais dos serviços sociais e de saúde demandados, por exemplo, pelo processo de envelhecimento, criando, portanto, um grande nicho de acumulação de capital por meio de planos e serviços de previdência e saúde para este público, os sistemas universalistas identificam a centralidade do Estado como provedor e responsável pelo cuidado e proteção social dos idosos (BARBOSA FILHO; LAFAYETTE; NASCIMENTO, 2017).

A política de saúde vem sofrendo as inflexões do processo de contrarreforma do Estado desde os anos 1990. A contrarreforma do Estado constitui-se numa resposta mundial do capitalismo que integra o conjunto de mecanismos de enfrentamento à crise estrutural iniciada nos anos 1970 (HARVEY, 2008). Desde os anos 1990, difundida pelas agências multilaterais, dentre elas o Banco Mundial, a contrarreforma neoliberal atinge o Estado brasileiro intensificando as suas mais perversas características. Um Estado historicamente ausente e mínimo em relação à proteção social dos trabalhadores, além de profundamente autoritário, precisava minimizar-se, de acordo com os preceitos produzidos e reproduzidos pelos aparelhos privados de hegemonia nacional e internacional do capital (IAMANOTO, 2007)

No Brasil, a política de saúde sempre teve uma racionalidade fragmentada, em geral, curativa, hospitalocêntrica e medicocêntrica, centrada no indivíduo, onde a lógica dos interesses privados, principalmente a partir do regime autocrático pós-1964, estava presente, institucionalizando e legitimando, assim, a perspectiva liberal de saúde. Aquela que reduz o direito à saúde a um conjunto de serviços a ser providos por meio de recursos financeiros do indivíduo/ou da família. Restando ao Estado intervir apenas quando os demais meios de inserção falhassem. Mesmo assim, a intervenção do Estado, segundo a perspectiva liberal de saúde, deveria ser restrita e não deveria se configurar como um direito social do cidadão ou como uma obrigação do Estado (BARBOSA FILHO \& ROCHA, 2016; BRAVO, 2010).

Essa perspectiva de saúde ocasiona o esvaziamento do conteúdo social, político e econômico do processo saúde-doença, tendendo a atribuir às preferências e estilos de vida individuais as principais causas de adoecimento e morte. As posições majoritariamente seguidas pela saúde pública tradicional e pela educação sanitária vão nesse sentido, ao afirmarem que os indivíduos são livres para escolher seu local de moradia, condições de trabalho, seus comportamentos e a exposição a situações de vulnerabilidade. Dessa forma, para os (neo)liberais os sistemas de saúde não deveriam ser os únicos 
responsáveis pela intervenção no processo saúde-doença. Para eles, a intervenção do Estado no processo na proteção à saúde deve ser mínima, não deveria se configurar como um direito social e o mercado, família e comunidade devem ser os principais provedores da atenção em saúde (BARBOSA FILHO \& ROCHA, 2016; MIOTO, 2010).

A concepção original do Sistema Nacional de Saúde do Brasil rompe com a perspectiva liberal de saúde e se volta à intervenção nas determinações e determinantes sociais históricos do processo saúde-doença. Desta forma, relaciona condições de saúde da sociedade às relações sociais vivenciadas por estas, apontando que as desigualdades sociais inerentes às sociedades capitalistas expressam desigualdades sociais inclusive na saúde (BARATA, 2009; BARBOSA FILHO \& ROCHA, 2016).

\begin{abstract}
As desigualdades sociais em saúde não são nenhuma novidade. Elas vêm sendo documentadas há muito tempo, principalmente a partir do século XIX. As condições políticas e sociais que surgiram com o capitalismo, em sua fase de produção, foram favoráveis ao tema, seja pelas péssimas condições de vida da classe trabalhadora, seja pelo ideário político associados às revoluções burguesas. A contradição entre os valores de igualdade, fraternidade e liberdade, e a dura realidade de vida da maioria da população nos países industrializados possibilitou aos chamados reformadores sociais, socialistas utópicos e comunistas, farto material para denunciar as injustiças sociais em vários campos inclusive na saúde (BARATA, 2009, p. 13).
\end{abstract}

No que tange as políticas de saúde em relação a população idosa, essas têm início nos anos 1980, durante o processo de formulação do SUS. A partir deste momento, se inicia a expansão à saúde dos idosos, entretanto, em uma organização de trabalho predominantemente centrada no atendimento médico individual e direcionado às doenças crônicas degenerativas.

Para responder às crescentes demandas da população que envelhece, foi criada a Política Nacional do Idoso (PNI), a partir da regulamentação do SUS, com o objetivo de assegurar os direitos sociais à pessoa idosa, criar condições para promover sua autonomia e reafirmar seu direito à saúde de maneira integral, nos níveis de atenção à saúde.

Apesar dos avanços obtidos com a formulação do SUS nas esferas das políticas públicas de saúde na década seguinte, 1990, a hegemonia das ideias neoliberais questionou a materialização do Projeto de Reforma Sanitária (BRAVO, 2008). Esta tendência de negação do conteúdo reformadorprogressista é aprofundada nos anos 2000 , inviabilizando a materialização do direito à saúde (BRAVO, 2010).

$\mathrm{Na}$ direção social oposta aqui defendida e ao Projeto do SUS da Reforma Sanitária, autores como Mello (2011) vêm defendendo as chamadas inovações gerenciais e operacionais do SUS. Para ele, na Política de Saúde estão em curso substantivas inovações ${ }^{3}$ que têm como marco não só o cenário da reforma do 
Estado, a redução de suas funções e o controle do gasto público, como também fatores internos, potencializados pela dinâmica do setor saúde e decorrentes da implementação do SUS.

Dessa forma, o autor supracitado afirma as perspectivas atualmente hegemônicas no SUS: a tecnicista, gerencial e pragmática, ao não problematizarem que sujeitos sociais estão fomentando essas "inovações" e essa "dinâmica interna" da Política de Saúde, as parcerias público-privadas e a despolitização das instâncias de controle social, que acompanham a implantação dessas novas modalidades de gestão. Estas inovações põem em risco a materialização do SUS como direito universal e não contributivo de cidadania (BARBOSA FILHO \& ROCHA, 2016; BRAVO, 2010; MOTA, 2012).

Mesmo assim, tais "inovações" nos modos de organizar a atenção à saúde vêm sendo consideradas indispensáveis à materialização do SUS por dois motivos: em primeiro lugar, pela necessidade de qualificar o cuidado por meio das denominadas "inovações produtoras de integralidade da atenção". Entre elas, se destacam: a assistência domiciliar, a diversificação das tecnologias de saúde e a articulação da prática dos diferentes profissionais e esferas da assistência em saúde.

Em segundo lugar, pela necessidade de adotar modos mais eficientes, eficazes e efetivos de utilizar os recursos destinados à política de saúde, considerando que o modelo hegemônico de atenção à saúde - centrado em procedimentos e não na promoção da saúde, no direito a ter uma vida saudável - implica investimentos crescentes, particularmente em função do envelhecimento da população, da transição epidemiológica e, sobretudo, da incorporação tecnológica orientada pela lógica do mercado (NASCIMENTO, 2012). É necessário apontar que nessa busca por eficiência, eficácia e produtivismo, o SUS assume como modelo a racionalidade das organizações do mercado (ANDREWS, 2010; BARBOSA FILHO, 2013; BRAVO, 2010). Dessa forma, despolitizando o debate acerca da saúde como direito de cidadania e a relação organicamente conflituosa entre capitalismo e democracia substancial.

Neste entendimento, especialmente trabalhado por Ellen Wood (2009), o avanço da democracia só se torna substancial quando esta desmercantiliza necessidades sociais dos cidadãos, alçando-os a categoria de direitos concretos. Por isso, a autora defende que democracia, direitos substantivos e avanço do capitalismo são incompatíveis. É o que se passa a tratar no próximo item, sobre a tensão entre direitos formais e direitos concretos na sociabilidade do capital.

\section{Justiça formal ou justiça concreta? uma análise a partir da perspectiva}




\section{marxista dos direitos humanos e sociais.}

Os direitos sociais dos idosos, que se dá no interior de uma sociedade desigual, sociedade esta que, ao invés de lidar com a desigualdade no sentido de eliminá-la, aprofunda-a, se valendo, para tanto, entre outras estratégias de controle, de uma visão apenas formal de justiça e não de sua concretização, só podem ser efetivados com o enfrentamento dessa questão, qual seja, a materialização de tais direitos.

Em sua teoria Marx (1818-1883) reconhece dois tipos de igualdade: um se pauta no princípio "de cada qual segundo sua capacidade, a cada qual segundo o trabalho realizado". O outro se baseia no princípio "de cada qual segundo sua capacidade, a cada qual segundo suas necessidades" (Marx, 1977, p. 232-233). Veja-se que, nos dois tipos de igualdade, ele considera "de cada qual segundo sua capacidade", ou seja, em qualquer sociedade, é justo que se exija de cada um conforme sua capacidade 4 . No entanto, para ele, esse princípio só se realiza na sociedade pós-revolucionária, saindo dos marcos da sociedade capitalista, seja no socialismo ou em sua fase mais avançada que é o comunismo.

Isso porque, apesar de considerar uma grande evolução a revolução burguesa, na medida em que rompe com o feudalismo no qual uns trabalhavam e outros não, a exemplo da aristocracia, o trabalho não é exigido de cada qual segundo sua capacidade, mesmo que o espírito do capitalismo seja de que todos trabalhem, até os empresários, e trabalhem muito para desenvolver a riqueza, ocorre o fato de que muitos com capacidade não trabalham por viverem do trabalho explorado dos outros e ainda, muitos com capacidade de trabalhar não o fazem por falta de emprego resultante do modo de produção estabelecido, que exige sempre um exército de reserva de mão de obra como manobra para baixar o preço do trabalho pago.

Considerando então os dois tipos de igualdade, ou seja, todos trabalharem de acordo com sua capacidade e para cada um segundo o trabalho realizado ou segundo suas necessidades, nos dois casos, o tratamento dos direitos para as pessoas idosas, deveria considerar ao menos suas limitações de capacidades físicas e, nesse caso, necessário seria se pautar pela máxima de "a cada qual segundo suas necessidades".

Esses tratamentos, porém, só poderão se concretizar numa sociedade alternativa ao capitalismo, com a eliminação de todos os critérios pelos quais a produção e a distribuição têm sido feitas, isto é, quando estes critérios atuais da sociedade burguesa forem considerados ilegítimos e injustos. Nesse raciocínio, então, fica claro o entendimento de Marx sobre como a igualdade é mediada pelas concepções de justiça em disputa na sociedade. 
Em sua "Crítica ao Programa de Gotha", Marx afirma que as relações jurídicas surgem das relações econômicas e demonstra como, ao se permitir numa sociedade, que uns se tornem donos das condições materiais de trabalho, o sentido de justiça admite também que o homem seja escravo de outros homens, na medida em que um só possui sua própria força de trabalho e depende totalmente dos outros homens que detêm os meios de produção.

\begin{abstract}
O trabalho não é a fonte de toda riqueza. A natureza é a fonte (...), o trabalho é a manifestação de uma força natural, da força de trabalho do homem (...) que é efetuado com os correspondentes objetos e instrumentos. Na medida em que o homem se situa de antemão como proprietário diante da natureza, primeira fonte de todos os meios e objetos de trabalho, e a trata como possessão sua, seu trabalho converte-se em fonte de valores de uso, e, portanto, em fonte de riqueza. Os burgueses têm razões muito fundadas para atribuir ao trabalho uma força criadora sobrenatural; pois precisamente do fato de que o trabalho está condicionado pela natureza deduz-se que o homem que não dispõe de outra propriedade senão sua força de trabalho, tem que ser, necessariamente, em qualquer estado social e de civilização, escravo de outros homens, daqueles que se tornaram donos das condições materiais de trabalho. E não poderá trabalhar, nem, por conseguinte, viver, a não ser com a sua permissão. (MARX, 1977, p. 227 - o destaque é do próprio Marx).
\end{abstract}

No modo de produção capitalista, "as condições materiais de produção são entregues aos que não trabalham sob forma de propriedade do capital e propriedade do solo, enquanto a massa é proprietária apenas da (...) força de trabalho". (MARX. 1977, p. 233). A distribuição depende, e é consequência, do modo de produção. Porém, mesmo numa sociedade que supere o capitalismo, na qual os meios de produção sejam coletivizados, o princípio de distribuição ainda não pode ser igual numa primeira fase, que se configura no socialismo, ao da sua etapa mais avançada que é o comunismo. Num primeiro momento, a distribuição é feita a cada qual segundo o trabalho realizado, (...) este direito igual continua trazendo implícita uma limitação burguesa. $O$ direito dos produtores é proporcional ao trabalho que prestou; a igualdade, aqui, consiste em que é medida pelo mesmo critério: pelo trabalho. (MARX, 1977, p. 232 negrito no original).

Esse primeiro tipo de distribuição, não equivale ainda a uma igualdade plena, totalmente justa, que seria o tratamento igual, porque, se cada um só recebe pelo trabalho realizado, como ficam os que não têm a mesma capacidade? A capacidade e o talento de cada um são muito diversos, além disso, podem ser inatos, ou seja, naturais, de cada indivíduo como as diferenças no aspecto da força física, idade, saúde etc., dependendo também das condições ambientais, das situações familiares, e, nestas situações, a capacidade de trabalho diminui ou inexiste, como é o caso das crianças, dos idosos, dos doentes físicos ou mentais, entre outros. Sendo assim, capacidade 
distinta implica em potenciais e limites distintos, por consequência, menos capacidade de trabalho, menos recebe. E, é assim que ocorre no primeiro tipo de igualdade.

Outro aspecto é a consciência. Nessa primeira fase, trata-se de corresponder a uma etapa do desenvolvimento da consciência individual e coletiva. Os marxistas tratam o problema das desigualdades sociais vendo a desigualdade como um problema crônico do capitalismo, um problema que ainda é inevitável numa sociedade socialista, que Marx chama, na mesma crítica, de socialismo inferior ou de socialismo de primeira fase. Inferior no sentido de etapa do socialismo, um socialismo ainda inicial, logo após a revolução, portanto um socialismo que ainda herda algumas mazelas da sociedade da qual ele se descolou.

Que característica teria essa ideia de igualdade e desigualdade nesse socialismo inferior? A principal é o princípio de distribuição que ainda é feito com base no trabalho, primeiro no sentido de reeducação das pessoas, para elas terem estimulo para o trabalho e descobrir as virtudes emancipatórias do trabalho realmente livre, isto é, uma ambiência social na qual o trabalho não seja uma mercadoria, o que requer uma sociedade dos produtores.

É de se notar que, no socialismo de primeira fase, não se pode falar ainda numa construção plena da justiça na medida em que as pessoas que vão construir esse socialismo ainda trazem a ideologia, a consciência de outra sociedade, e por isso que há luta de classe do socialismo de primeira fase, porque ainda haverá aqueles resquícios da sociabilidade burguesa pelos quais algumas pessoas ainda vão - o preguiçoso, por exemplo - encostarem-se aos mais eficientes, o que não tem uma consciência política mais elevada para 0 trabalho social vai render menos, o que aponta para a questão, mesmo no socialismo, da luta de classes.

Então, nessa primeira fase, a distribuição não é - ainda - uma distribuição igual para todos. É uma distribuição conforme o trabalho, portanto uma distribuição que, eventualmente, ainda tem estimulo ao trabalho, a chamada emulação, e ainda tem que se travar uma luta política e ideológica em relação aos que resistem à nova sociedade, o que pode implicar em algum nível de coerção para que eles se integrem ao esforço social. A intensificação desse nível de coerção, evidentemente, não é algo abstrato, é algo que depende da resistência desses setores ao avanço da luta de classes e de uma série de outros fatores e que é feito em cada país de acordo com sua realidade.

Nessa primeira fase instaura-se um princípio de distribuição que não equivale ainda a uma igualdade plena, que seria um tratamento absolutamente igual. Note-se que já há, nessa nova sociabilidade, do socialismo de primeira fase, uma diferença substancial em relação à igualdade capitalista, a qual é - 
ela mesma - uma igualdade abstrata na medida em que formalmente aplicada a todos os indivíduos, resulta, na prática, deles recebem um tratamento desigual materialmente falando.

O outro tipo de igualdade, já numa etapa mais avançada da sociabilidade humana, é aquela que se baseia no princípio "de cada qual segundo sua capacidade, a cada qual segundo suas necessidades", que corresponde à fase superior do socialismo, pois

\begin{abstract}
(...) o direito não pode ser nunca superior à estrutura econômica nem ao desenvolvimento cultural da sociedade por ela condicionado. Na fase superior da sociedade comunista (...) quando, com o desenvolvimento dos indivíduos em todos os seus aspectos, crescerem também as forças produtivas e jorrarem em caudais os mananciais da riqueza coletiva [só então - acréscimo dos autores do presente artigo] a sociedade poderá inscrever em suas bandeiras: De cada qual, segundo sua capacidade; a cada qual, segundo suas necessidades. (MARX, 1977, p. 232- 233).
\end{abstract}

Isso porque só no comunismo é possível um tratamento igual aos seres humanos com todas suas necessidades forçosamente desiguais, porque a individualidade será sempre singular e uma socialização superior não nega o indivíduo e sim o individualismo. É fundamental fortalecer o indivíduo até porque, numa lógica de indivíduos fracos não se pode esperar a construção de coletivos fortes. E essa etapa do desenvolvimento só pode ser possível a partir de uma elevação enorme das forças produtivas, um avanço nas relações de produção a tal ponto que seja possível criar um fundo social e econômico, que permita que essas desigualdades sejam eliminadas.

As classes exploradoras e o individualismo, numa sociedade de socialismo superior, ou serão eliminados ou serão tidos como resquícios primitivos de um período de barbárie, pelo que o pré-requisito de tal sociedade será a eliminação desses resquícios, porque a base de sua existência que era a propriedade privada, o controle privado dos meios de produção deixou de existir, embora - até hoje - não se conheça nenhuma sociedade de nível absolutamente superior, ou seja, uma sociedade de comunista, porque isso pressupõe uma transformação mais geral do mundo.

Nessa sociedade superior, então, se espera que o desenvolvimento das relações de produção e das forças produtivas seja tal, que se passa a ter um fundo de reserva público suficiente para dar conta das crianças, dos velhos e dos doentes, sem com isso eles serem considerados parasitas do esforço social.

Uma sociedade que assegure meios de vida adequados a todos implica também na superação do desejo egoísta universal de possuir cada vez mais, na ultrapassagem da hierarquização de poder e prestígio, na perspectiva de motivação para valores não só materiais e na plena garantia, a todos, de 
atividades satisfatórias e relações sociais que respaldem concretamente tais atividades e meios de vida. Isso seria o que se pode chamar de viver sob um modelo material e formalmente justo.

Pelo exposto, fica explicito, portanto que, para Marx, justiça equivale a condições concretas de igualdade humana, passando não apenas pelas garantias formais de igualdades - essas, necessárias, mas não suficientes mas, concomitantemente, garantindo sua plena concretização, pela via da plenitude dos direitos sociais e humanos. E é, nesse sentido que Marx critica a concepção liberal sobre o direito, refletida na tensão entre justiças formal e concreta.

Cabe, ainda nessa parte, esclarecer a distinção entre justiça formal e justiça material: Quando se trata de Justiça formal é de se notar que ela é puramente procedimento (e procedimento é forma), ou seja, há regras que garantem a possibilidade de se demandar por um dado direito, mas não significando isso - ainda que o indivíduo tenha 'direito àquele direito' - que o mesmo venha a ser implementado. Essa distinção, que permeia e é cara a toda a tradição liberal, sempre buscou nublar, que a efetivação de uma dada garantia implica em dotar a mesma de seu elemento material. Por conta disso, muitas conquistas no plano social, por vezes, não saem do papel e, na conjuntura atual do Brasil, até do papel estão querendo retirar a exemplo da proposta de reforma da previdência atingindo o direito de aposentadoria.

\section{Considerações finais}

Para além dos aspectos técnicos e gerenciais das políticas e programas voltados à concretização do direito à saúde dos idosos, este artigo buscou fornecer subsídios teórico-conceituais para as discussões acerca da garantia do direito e da materialização das políticas sociais, em especial a política de saúde. Nesse sentido, entende-se que a efetivação dos direitos sociais dos idosos entra em choque com a dinâmica do capitalismo e da sua forma política, o Estado burguês.

Nesse contexto, pode-se afirmar que o Programa Melhor em Casa, materializado pelo SAD, surge como uma resposta, uma estratégia de contenção de demanda, fundamental para reduzir o pleito por serviços hospitalares e de fomento à constituição de parcerias entre o sistema de saúde, famílias e comunidades, desresponsabilizando o Estado no que diz respeito à provisão de cuidados em saúde. Portanto, um Programa Federal característico de uma contrarreforma do Estado, que expressa novas determinações e demandas ao conjunto dos profissionais da saúde. Além disso, torna-se um espaço não só de 
afirmação dos direitos dos idosos à saúde integral e humanizada, mas de resposta às necessidades do Estado em conter investimentos no campo da saúde pública, garantindo sua "saúde fiscal".

Dessa forma, o estudo do entendimento da noção de justiça a partir da tradição marxista, conduz ao desvelamento das manobras conservadoras, permite aos que se valem dessas ferramentas teóricas perceberem mais claramente a tensão entre apenas reproduzir os sentidos liberais que defendem os direitos na formalidade, o que na prática, atende apenas as necessidades de reprodução do capital, ou reinterpretar o significado do direito para o interesse da maioria da sociedade.

$\mathrm{E}$, neste sentido, trata-se de exigir que se assegure a universalidade de acesso aos bens e serviços necessários à sobrevivência da espécie, bens estes que superam aqueles ofertados, hoje, à imensa maioria da humanidade, vitimada pela lei geral de acumulação de capital, com a lógica neoliberal, através de programas e políticas sociais focalizadas e paliativas, como as que vem sendo formuladas para atender às necessidades sociais da população idosa de forma fragmentada e incipiente. Assim, Marx concebe os direitos humanos e sociais apenas concretizados no horizonte de superação da hegemonia do capital, quando, com o desenvolvimento dos indivíduos, se desenvolverem, plena e concomitantemente com as forças produtivas. Dessa forma a luta por direitos só adquire concretude real quando assume uma direção anticapitalista.

Sendo assim, o envelhecimento da classe trabalhadora nos marcos do capitalismo corresponde a uma demanda que, sem articulação política e luta social, não pode obter resultados significativos através de reformas nos moldes de um Estado burguês, pois esta configuração redimensiona o tempo de vida do trabalhador ao tempo em que este pode produzir riquezas, mercadorias, bens e serviços necessários à reprodução do capital.

Ao final é importante se ter em conta que a consigna "a cada um segundo sua necessidade" implica num reconhecimento como uma questão de fato - por parte de Marx - de determinadas desigualdades geradas por necessidades diferentes e resultantes de diferenças dadas e não construídas pela sociabilidade capitalista - uns são - para reforçar um exemplo dado anteriormente - velhos, outros doentes, outros são recém-nascidos e todos, nessas condições, precisam de trato diferenciado, o que, como se vê, não compromete a tese central do campo marxista em defesa do princípio geral da igualdade.

O que justificaria, pois, a luta por ela, além de todas essas questões aqui colocadas?

Ora, não se trata - em nenhum dos exemplos mencionados - de uma desigualdade burguesa, derivadas do lugar de classe de ninguém, menos ainda 
de poder, mas de desigualdades derivadas ou de necessidades especiais ou da natureza mesma dos seres humanos (o tratamento diferenciado, por exemplo, a uma mulher grávida ou que amamenta é uma conquista da civilização), assim como o direito à aposentadoria e proteção social integral aos idosos.

Portanto, desigualdades naturais existirão em qualquer sociedade e, inclusive, naquelas de socialismo avançado, e mesmo no comunismo, pois em todas as épocas não deixarão de existir idosos, crianças, deficientes, pessoas doentes, as quais receberão, não conforme seu trabalho, mas, conforme suas necessidades e sem ignorar que, com o avanço da ciência e da técnica, algumas dessas "barreiras naturais" (para se apropriar de uma expressão de Lukács, na sua "Ontologia") poderão - e serão - superadas.

Interessa também destacar - para dar conta do problema da justiça e igualdade aqui abordadas - é que os beneficiários de acordo com as necessidades, não sejam considerados, ou enquanto parasitas, ou enquanto alvos da caridade pública como - num caso, no outro ou em ambos - são vistos na sociabilidade capitalista. Nesse sentido, vale recordar que as primeiras ações públicas assistenciais do Estado brasileiro voltadas aos idosos pobres tinham caráter meramente assistencialista e forte julgamento moral e estigmatizador sobre os usuários.

Eles são - e só podem ser assim vistos, como portadores de desigualdades intrínsecas a uma dada condição de sua própria humanidade, pois mesmo os que estão em condição de trabalhar, uns têm mais habilidades e outros menos, assim como a condição de saúde, da força do corpo, entre outras, são desigualdades que precisam ser consideradas e respeitadas. Por isso tratase de localizar, precisamente, a contradição existente entre uma concepção de justiça que vise eliminar as desigualdades formais e materiais e a práxis no interior de uma sociedade ao mesmo tempo injusta e desigual.

Cabe, pois, que se reitere a distinção entre justiça formal e justiça material / concreta: a primeira é puramente procedimental, isto é, se preocupa com a sua exterioridade, com seu aspecto formal - visto que procedimento é meramente forma.

O que isso significa do ponto de vista das práticas sociais humanas? Significa a ascensão ou priorização tão somente de regras que garantam a possibilidade de se demandar por um dado direito sem que isso resulte que o indivíduo tenha em sua vida empírica, isto é, concretamente, a aquele direito, ou seja, o fato de tê-lo formalmente não resulta que o mesmo venha a ser implementado. Essa distinção, sub-reptícia, que caracteriza e é tão preciosa no interior da tradição liberal, é tipicamente ideológica e busca ocultar o fato elementar pelo qual ter direito a um dado direito reduz-se, no capitalismo, a poder pleitear por ele sem isso implicar ou comprometer o Estado em dotar o corpo 
social de seu elemento material, isto é, de sua concretização.

Com isso, evidencia-se que a reconstrução das noções de justiça e igualdade permite, antes de tudo, demonstrar como esses conceitos são tratados de modo formal e abstrato - isto é, alienado - na vivência do capital a qual, até nossos dias, segue caudatária da visão liberal oitocentista, e dela não poderia ser diferente visto que, qualquer outro tratamento dessa sociabilidade cindida evidenciaria e solaparia os seus próprios fundamentos.

Assim, e para compreender as políticas e os direitos sociais dos idosos à saúde sob o capitalismo como uma trajetória de conflitos entre justiça formal e concreta, é que se afirma aqui haver o embate entre a concepção dos direitos da pessoa idosa e a tensão no que diz respeito a sua materialização, por uma política que minimiza a responsabilidade do Estado como parte de uma contrarreforma, tornando-se um espaço não de afirmação dos direitos à saúde integral e humanizada deste público, mas de resposta à necessidade do próprio Estado. Na prática, esvaziando os próprios direitos.

\section{Referências}

BARBOSA FILHO, Evandro Alves. Coalizão de forças, discursos e conflitos: uma análise do gerencialismo na gestão do consórcio público intermunicipal de saúde do Sertão do Araripe pernambucano (CISAPE). 2013. 143 f. Dissertação (Mestrado) - Curso de Mestrado em Serviço Social, Departamento de Serviço Social, Universidade Federal de Pernambuco, Recife, 2013.

.; ROCHA, Maria Solange Guerra. Três décadas de neoliberalismo e de lutas contra a epidemia de hiv e aids na periferia capitalista: uma análise crítica da África do Sul, Brasil e Moçambique. In: Ana Cristina de Souza Vieira; Solange Rocha; Evandro Alves Barbosa Filho. (Org.). HIV Aids e as teias do capitalismo, patriarcado e racismo: África do Sul, Brasil Moçambique. 1ed.Recife: Editora Universitária da UFPE, 2016, v. 1, p. 27-155.

; NASCIMENTO \& SORIANO. Formações Discursivas e ldeológicas da Atenção Domiciliar no SUS: uma Análise Crítica do Programa Melhor em Casa. VI Congresso Brasileiro de Ciências Sociais e Humanas em Saúde Coletiva. Rio de Janeiro, RJ, 2013.

. LAFAYETTE, Maria da Conceição. \& NASCIMENTO, Michelli Barbosa. A Saúde do Idoso nos Serviços de Atenção Domiciliar no Contexto de Contrarreforma da Saúde: um estudo de caso. In: TEIXEIRA, Solange Maria. 
Envelhecimento na Sociabilidade do Capital. Ed. Papel Social, 2017.

BARATA, Rita Barradas. Por um processo de descentralização que consolide os princípios do Sistema Único de Saúde. Epidemiol. Serv. Saude, Belo Horizonte, v.13, n.1, p.15-24, 2009.

BEAUVOIR, Simone de. A velhice. Rio de Janeiro: Nova Fronteira, 1990.

BRASIL. Portal Brasil: economia e emprego, 2016. Disponível em: < http://www.brasil.gov.br/economia-e-emprego/2016/12/em-10-anos-crescenumero-de-idosos-no-brasils

. Lei no 8.842, de 04 de janeiro de 1994. Dispõe sobre a polltica nacional do idoso, cria o Conselho Nacional do Idoso e d. outras providíncias. Brasília DF, Janeiro de 1994.

. Estatuto do idoso: lei federal no 10.741, de 01 de outubro de 2003. Brasília, DF: Secretaria Especial dos Direitos Humanos, 2004.

. Diário Oficial da União. Lei no 8080/90. Dispõe sobre as condições para promoção, proteção e recuperação da saúde, a organização e o financiamento dos serviços correspondentes e da outras providências. Brasília DF, 19 de setembro de 1990.

. Lei 8.142. Dispõe sobre a participação da comunidade na gestão do SUS e dá outras providências. Brasília DF, 28 de dezembro de 1990.

Disponível

Constituição Federal de 1988. Promulgada em 5 de outubro de 1988.

$<$ http://www.planalto.gov.br/ccivil 03/constituicao/constituição.htm>.

em

BRAVO. Maria. Inês. Souza. Política de Saúde na atual conjuntura: modelos de gestão e agenda para a saúde. Rio de Janeiro: 2008, Adufrj.

. A saúde no Brasil e em Portugal na atualidade: o desafio de concretizar direitos. Serviço Social e Sociedade, São Paulo, n. 102, p.5-21, 01 abr. 2010.

. Política de saúde no Brasil. In: MOTA, et al (orgs.). Serviço Social e saúde: formação e trabalho profissional. São Paulo: Cortez, 2006. 
ENGELS, Friedrich; KAUTSKY, Karl. O Socialismo Jurídico. São Paulo: Boitempo, 2012.

FALCÃO, Raquel. Serviço Social e Direitos Humanos: O sentido de justiça e igualdade numa sociedade desigual. (a partir da crítica marxista ao conceito de direitos humanos). UFPE, 2014.

HARVEY, David. A produção capitalista do espaço. $2^{\underline{a}}$ ed. São Paulo: Anna Blume, 2005.

. O neoliberalismo: história e implicações. São Paulo: Loyola, 2008.

HIRSCH, Joachim. Teoria materialista do Estado: processos de transformação do sistema capitalista de Estados. Rio de Janeiro: Revan, 2010.

IAMAMOTO, Marilda Vilela. Serviço Social em tempo de capital fetiche. São Paulo: Cortez Editora, 2007.

LUKÁCS, Gyorgy. Para uma Ontologia do ser social I. Tradução Nélio Schneider, Ivo Tonet, Ronaldo Vielmi Fortes. -1를 Edição - São Paulo: Boitempo, 2012.

MARX, Karl. Crítica ao programa de Gotha. In: Marx e Engels - Textos Volume I. São Paulo: Edições Sociais, 1977.

MELLO, Guilherme. Arantes. Gestão do conhecimento e da inovação no setor público. In: IBAÑEZ, N.; ELIAS, P. E. M.; SEIXAS, P. H. Política e Gestão Pública em Saúde. São Paulo: Hucitec-cealag, 2011. p. 446-479.

MIOTO, Regina Célia. A Família como Referência nas Políticas Públicas: dilemas e tendências. In: TRAD, Leny A.(Org.). Família Contemporânea e Saúde: significados, práticas e políticas públicas. Rio de Janeiro: FIOCRUZ, 2010.

MOTA, Ana Elisabete. Cultura da crise e seguridade social: um estudo sobre as tendências da previdência e assistência social brasileira nos anos 89 e 90. 3. ed. São Paulo: Cortez, 2005.

NASCIMENTO, Michelli Barbosa do. Idosos Assistidos no Serviço de Atenção Domiciliar: Integralidade das ações em saúde. UFPE, 2016. 
SPOSATI, Aldaíza; BONETTI, Dilsea Adeodata.; YASBEK, Maria Carmelita.; FALCÃO, Maria do Carmo B. C. Assistência na trajetória das políticas sociais brasileiras: uma questão em análise (5ª ed.). São Paulo: Cortez, 1992.

SOARES, Raquel Cavalcante. Contrarreforma na Política de Saúde e Prática Profissional do Serviço Social nos Anos 2000. In: MOTA, Ana Elizabete (org.). As ideologias da contrarreforma e o serviço social. Recife: Ed. Universitária da UFPE, 2010.

WOOD, Ellen Meiksins. Estado, Democracia e Globalização. In: BORON, Atílio A.; AMADEO, Javier; GONZÁLES, Sabrina (Org.). A teoria Marxista Hoje: problemas e perspectivas. Buenos Aires: Expressão Popular/Clacso Livros, 2006. p. 381-393.

\footnotetext{
1 Neste artigo será usado também o termo "velho", assumindo uma posição politicamente contrária aos eufemismos que tentam polir o termo como se fosse defeito ou deficiência. Considera-se que não é depreciativo usar a palavra velho referenciando a pessoa idosa, mas que termos como "terceira idade" (que não diz respeito à realidade brasileira) ou "melhor idade", são formas de amenizar o descaso e o preconceito com este segmento.

2 Vale ressaltar que dos 30 programas assistenciais desenvolvidos pelo Estado Brasileiro entre 1955 e 1985, apenas este abordou a questão do envelhecimento na condição de pobreza (SPOSATI et al, 2014).

${ }^{3}$ Sobre a natureza burguesa dessas "inovações" no SUS, ver Barbosa Filho (2013) e Soares (2010).

${ }^{4}$ Sobre o debate acerca da justiça social e dos direitos humanos fundamentada na tradição marxista, ver Falcão (2014).
} 